\title{
EDUCAÇÃO SEXUAL, CT\&i: UM BREVE ESTUDO TEÓRICO E UMA PROPOSTA DE APLICAÇÃO
}

\author{
EDUCACIÓN SEXUAL, CT\&I: UN BREVE ESTUDIO TEÓRICO Y UNA PROPUESTA \\ DE APLICACIÓN
}

\section{SEXUAL EDUCATION, CT\& $:$ : A BRIEF THEORETICAL STUDY AND A PROPOSAL FOR APPLICATION}

\author{
Claudionor Renato da SILVA ${ }^{1}$
}

RESUMO: A problemática deste estudo, apesar ainda inicial e incipiente, é a possibilidade de aproximação da Educação Sexual aos pressupostos da CT\&i. Se propõe um currículo para a educação escolar e para os espaços não escolares que nasça não só das pesquisas e produções da área da Educação Sexual, mas que seja expandida para reflexões e produções de teorias sobre a "indústria da sexualidade", com as inovações e tecnologias científicas fruto do avanço da informação computadorizada. Nessa proposta se elabora um conceito provisório de "Educação Sexual Científica" (ESC) que, em seu projeto inicial, pretende se configurar nos moldes da Alfabetização Científica. Com metodologia de base bibliográfica, a problemática da pesquisa é respondida em duas frentes: a primeira frente, aproximar a área da Educação Sexual à CT\&i a partir da Epistemologia da Ciência. Na segunda frente, propor uma metodologia nos aportes da Alfabetização Científica. Um dos principais resultados é o campo de desafios que se abrem para ser pensado um projeto teórico e metodológico de ESC, por exemplo, a digisexuality, as novas tecnologias "robossexuais", as plataformas digitais sexuais, com jogos e "sentidos" promovidos pela indústria, apoiando-se na ciência da sexualidade humana e atendendo ao bem-estar de seus usuários(as) individuais e coletivos. A principal conclusão é a possibilidade positiva (e "arriscada") dessa aproximação da Educação Sexual com a CT\&i, sobretudo em sua complementariedade ao aspecto emancipatório da sexualidade humana utilizado nas Ciências da Educação.

PALAVRAS-CHAVE: Educação sexual. CT\&i. Educação sexual científica.

RESUMEN: El problema de este estudio, que sigue siendo un estudio inicial e incipiente, es la posibilidad de aproximar la educación sexual a los supuestos de CT \& i. Se propone un plan de estudios para la educación escolar y para espacios no escolares que nace no solo de la investigación y producción en el área de Educación Sexual, sino que se expande para reflejar y producir teorías sobre la "industria de la sexualidad", con innovaciones y tecnologías científicas resultantes del avance de la información computarizada. En esta propuesta, se elabora un concepto provisional de "Educación Sexual Científica" (ESC), que, en su proyecto inicial, pretende configurarse en la línea de la Alfabetización Científica. Con una metodología basada en la bibliografía, el problema de investigación se responde en dos frentes: el primero, que lleva el área de Educación Sexual a CT\&i desde la Epistemología de la Ciencia. En el

${ }^{1}$ Universidade Federal de Jataí (UFJ), Jataí - GO - Brasil. Docente e pesquisador Unidade Acadêmica Especial de Educação (Curso de Pedagogia) e Unidade Acadêmica de Ciências Humanas e Letras (Programa de PósGraduação em Educação). ORCID: https://orcid.org/0000-0003-1693-4804. E-mail: claudionorsil@gmail.com

Temas em Educ. e Saúde, Araraquara, v. 16, n. 1, p. 40-50, jan./jun., 2020. e-ISSN 2526-3471. 
segundo frente, proponer una metodología en las aportaciones de la Alfabetización Científica. Uno de los principales resultados es el campo de desafios que se abren para un proyecto ESC teórico y metodológico, por ejemplo, digisexualidad, nuevas tecnologías "robosexuales", plataformas sexuales digitales, con juegos y "sentidos" promovidos por la industria., confiando en la ciencia de la sexualidad humana y atendiendo al bienestar de sus usuarios individuales y colectivos. La conclusión principal es la posibilidad positiva (y "arriesgada") de esta aproximación de la educación sexual con $C T \& i$, especialmente en su complementariedad con el aspecto emancipatorio de la sexualidad humana utilizada en las ciencias de la educación.

PALABRAS CLAVE: Educación sexual. CT\&i. Educación sexual científica.

ABSTRACT: The problem of this study, which is still an initial and incipient study, is the possibility of approximating Sexual Education to the assumptions of CT\&i. A curriculum is proposed for school education and for non-school spaces that is born not only from research and production in the area of Sexual Education, but that is expanded to reflect and produce theories about the "industry of sexuality", with innovations and scientific technologies resulting from the advance of computerized information. In this proposal, a provisional concept of "Scientific Sexual Education" (SSE) is elaborated, which, in its initial project, intends to be configured along the lines of Scientific Literacy. With bibliographic based methodology, the research problem is answered on two fronts: the first front, bringing the area of Sexual Education to CT\&i from the Epistemology of Science. In the second front, to propose a methodology in the contributions of Scientific Literacy. One of the main results is the field of challenges that open up for a theoretical and methodological SSE project, for example, digisexuality, new "robosexual" technologies, digital sexual platforms, with games and "senses" promoted by the industry, relying on the science of human sexuality and attending to the well-being of its individual and collective users. The main conclusion is the positive (and "risky") possibility of this approximation of Sexual Education with CT\&i, especially in its complementarity with the emancipatory aspect of human sexuality used in Educational Sciences.

KEYWORDS: Sexual education. CT\&i. Scientific sex education.

\section{Introdução}

O presente texto é um breve estudo teórico e uma proposta de aplicação da Educação Sexual sob uma perspectiva da Ciência, Tecnologia e Inovação, CT\&i.

$\mathrm{Na}$ frente do estudo teórico organiza-se a ciência como Epistemologia da Ciência, optando por um dos epistemólogos, para tratar da Educação Sexual, mas avança-se no conceito de ciência, ao abranger o que é e o que não é ciência segundo a Epistemologia da Ciência (Filosofia da Ciência) na extensão à Tecnologia e Inovação. Nesse avançar, analisa-se como a ciência da sexualidade tem dialogado com a ciência, a tecnologia e a inovação no sentido do bem-estar do indivíduo, em sua sexualidade. Ao se destacar a Educação Sexual neste prisma da CT\&i pretende-se transpor ao currículo da educação escolar e ao currículo possível dos 
movimentos sociais ou partidos políticos as bases da ciência da sexualidade. Nesse conjunto de produções em CT\&i estão, por exemplo, os aplicativos sexuais, os "robossex", enfim, tudo que traduza a comunicação, a internet em relação à sexualidade.

$\mathrm{Na}$ frente de aplicação está a proposta de se colocar a possibilidade de pensar esta Educação Sexual em CT\&i na Alfabetização Científica.

Com isso, é desta forma que o presente artigo está organizado, seguindo uma metodologia bibliográfica, segundo Sampieri, Collado e Lucio (2006), em que se aproveita de suas colocações sobre a permissibilidade de as pesquisas bibliográficas construírem definições, conceitos e até "quase" teorizações, a partir de formulações advindas de lacunas de obras selecionadas para a construção de um debate ou um discurso em determinado tema.

É exatamente o que se faz neste artigo, tendo duas seções centrais, sobre as frentes comentadas anteriormente, para concluir, ainda que brevemente, as possibilidades, ou não, de uma Educação Sexual que se aproxime da CT\&i, "extrapolando", diga-se, assim, a temática da Educação Sexual para além do escolar, abarcando os espaços formativos não escolares, com destaque aos movimentos sociais e partidos políticos, mas também "extrapolando" para as relações da ciência da sexualidade com a sociedade, a indústria, o sistema capital, os meios de comunicação mais diversos, a inovação, as políticas públicas e o debate social praxiológico geral e amplo que está no âmbito da Filosofia da Ciência na contemporaneidade, ou seja, se perguntar: para quem, para que e sob que custo ou valor toda a produção industrializada, inclusive do sexo e da sexualidade, são desenvolvidos?

\section{Ciência, Tecnologia e Inovação - um estudo teórico breve sobre a ciência da sexualidade humana}

O referencial para discussão da ciência, em particular, e da articulação ciência, tecnologia e inovação é de base inicial na Epistemologia da Ciência, a Filosofia da Ciência. Submete-se a Educação Sexual para uma especificidade de linha epistemológica em Filosofia da Ciência: epistemologia genética de Piaget, epistemologia de Foucault - esta epistemologia, bem presente e bem conhecida, entre os pesquisadores(as) dos estudos da área da Educação Sexual no Brasil (FOUCAULT, 1988) - epistemologias, enfim, que abarquem uma discussão em ciência da sexualidade humana. Que, por sua vez, são e serão transpostas ao currículo de uma proposta de Educação Sexual, seja para a educação escolar, seja para os espaços não escolares, especialmente, os espaços de empoderamento social e político. 
Avança-se, a partir daí para a complementariedade dos aspectos da tecnologia e da inovação, em que não há uma ordem entre eles, pois são intrinsecamente configurados, encontrando, na produção da ciência, o marco de sua essência (HALL, 1963; ALVES, 1981; RUSSETT, 1995; ROY; TEICH，1998; LATOUR，1996; 2000; 2001; ROGERS，2003; MORIN, 2005).

A articulação CT\&i fica evidente na fala de Rubem Alves e nos permite pensar a questão do senso comum referente ao uso da tecnologia disponível, o que inclui os produtos e serviços em sexualidade e sexo na sociedade do consumo, na sociedade contemporânea.

[...] a ciência é uma especialização, um refinamento de potenciais comuns a todos. Quem usa um telescópio ou um microscópio vê coisas que não poderiam ser vistas a olho nu. Mas eles nada mais são que extensões do olho. Não são órgãos novos. São melhoramentos na capacidade de ver, comum a quase todas as pessoas. [...] A ciência não é um órgão novo de conhecimento [...]. A aprendizagem da ciência é um processo de desenvolvimento progressivo do senso comum (ALVES, 1981, p. 9, grifo nosso).

Desta reflexão-problematizadora, encontramos apoio em Morin (2005), para quem,

[...] do ponto de vista epistemológico, é impossível isolar a noção de tecnologia ou téchné, porque bem sabemos que existe uma relação que vai da ciência à técnica, da técnica à indústria, da indústria à sociedade, da sociedade à ciência etc. E a técnica aparece como um momento nesse circuito em que a ciência produz técnica, que produz a indústria, que produz a sociedade industrial; circuito em que há, efetivamente, um retorno, e cada termo retroage sobre o precedente [...] (MORIN, 2005, p. 107, grifo nosso).

A ciência da sexualidade está presente nesse circuito que, como afirmam Parker e Aggleton (2007), no início do século XXI, deixou de ser algo biomédico para alcançar um patamar outro nas áreas sociais e políticas.

Os caminhos indicados por Morin (2005) para uma Epistemologia da Ciência, que, portanto, estando alinhada à Ciência da Sexualidade Humana, implica, em primeiro lugar, a tomada de consciência crítica, independente das fontes e das origens. Tudo, absolutamente tudo, desde políticas, até a própria Epistemologia, deve ser posto sob a crítica. Este primeiro indicador é decisivo para a consideração do próximo caminho, que Morin apresenta como segunda condição: a necessidade de elaborar uma ciência da ciência, em nosso projeto desenvolvido neste artigo, uma ciência da ciência da sexualidade, transposta para a Educação Sexual, que se convenciona aqui, Educação Sexual Científica.

O conhecimento do conhecimento científico comporta necessariamente uma dimensão reflexiva, que deve deixar de ser remetida à filosofia; que deve vir do interior do mundo científico [...]. Os diversos trabalhos de Popper, Kuhn, 
Feyerabend, Lakatos assinalam, como traço comum, o fato de mostrar que as teorias científicas, como os icebergs, têm enorme parte imersa, que não é científica, que é a zona cega da ciência, indispensável, entretanto, ao desenvolvimento da ciência.

Temos de caminhar para uma concepção mais enriquecida e transformada da ciência (que evolui como todas as coisas vivas e humanas), em que se estabeleça a comunicação entre objeto e sujeito, entre antropossociologia e ciências naturais. Poder-se-ia, então, tentar a comunicação (não a unificação) entre "fatos" e "valores"; para que tal comunicação seja possível, são necessários, por um lado, um pensamento capaz de refletir sobre os fatos e de organizá-los para deles obter conhecimento não só atomizado, mas também molar, e, por outro, um pensamento capaz de conceber o enraizamento dos valores numa cultura e numa sociedade (MORIN, 2005, p. 122, grifos nosso).

A Educação Sexual se articulará a CT\&i (WIEZWNBAUM, 1976; ASIMOV, 2014). Os caminhos da tecnologia e da inovação em sexualidade humana implicam em modernidade dos meios de comunicação. Um caminho sem volta, no mundo contemporâneo (SCUTT, 1990; DAVIS-FLOYD; DUMMIT, 1998; BEED, 2014).

Alguns exemplos desta expansão necessária ou aproximação necessária da Educação Sexual à CT\&i. Comecemos com o anúncio do Future of Sex²:

- Sexo remoto: brinquedos sexuais eletrônicos (vibradores inteligentes). São brinquedos sexuais conectados à Internet: beijos remotos e travesseiros conectados.

- Sexo virtual: mensagens de bate papo online e sexo em ambientes 3D. Também estão aqui os jogos sexuais modelo multiplayer. Um exemplo, o Red Light Center Game.

- Robôs, homens e mulheres, como máquinas sexuais, capazes de exprimir amor e emoções. São parceiros sexuais robóticos.

- Entretenimento imersivo: combinando o real com o virtual são os oferecidos streamings sexuais via câmeras, com realidade virtual ao vivo. O primeiro site a lançar o streaming foi o Pornhub, em 2016.

- Aumento da capacidade humana com implantes computacionais portáveis (próteses genitais e performances sexuais).

Outro exemplo: a digissexualidade (digisexuality). Este é outro tema interessante nesse universo da CT\&i a partir da ciência da sexualidade humana.

Neil McArthur e Markie Twist, no artigo “The Rise of Digisexuality” (MACARTHUR; TWIST, 2017) dão origem ao termo digisexuality que são as pessoas que optam por uma

\footnotetext{
${ }^{2}$ Na página de abertura, a mensagem: “A tecnologia está mudando a intimidade. Future of Sex convida você para uma conversa sobre o nexo de sexo, tecnologia e bem-estar". (Tradução nossa, aproximada). Disponível em: www.futureofsex.org. Acesso em: mar. 2020.
} 
vivência e um estar em sexualidade no campo virtual ou com robôs, seja para sexo ou para um inter-relacionamento.

No artigo, os autores denominam a digissexualidade como uma nova tecnologia sexual radical. Por que radical? Por excluírem totalmente o humano e a relação entre duas pessoas? Que racionalidade científica a área da Educação Sexual pode organizar? Todas perguntas, sem nenhuma resposta, a não ser, fomentar investigações e pesquisas; inicialmente, construtos teóricos na Educação Sexual, sob a perspectiva da CT\&i.

Uma proposta nesta direção é a Alfabetização Científica, que é abordada na seção seguinte.

\section{A proposta: educação sexual como alfabetização científica}

Desde Hurd (1998), passando por Anelli (2011) e utilizando-se da produção de Chassot, (2017) se estrutura uma proposta teórica e metodológica, nesta proximidade da Educação Sexual com as bases da CT\&i.

Carol Anelli (2011) cita Davis (1935), que organizou 14 objetivos específicos para o estudo, de modo geral, e seis características que identificam a atitude científica, portanto, atitudes em alfabetização científica. Muitos dos objetivos do estudo, traçados e identificados por Davis, são e estão articulados a atitudes esperadas por estudantes envolvidos no processo de ensino-aprendizagem em Ciências.

Vamos analisar o Quadro 1.

Quadro 1 - Objetivos do estudo e as características do estudo científico, suas atitudes

\begin{tabular}{|c|c|}
\hline $\begin{array}{l}\text { Objetivos específicos para todos os } \\
\text { estudantes }\end{array}$ & $\begin{array}{c}\text { Características do estudante com atitude } \\
\text { científica }\end{array}$ \\
\hline $\begin{array}{l}\text { 1. Comando de informações factuais } \\
\text { 2. Familiaridade com leis, princípios e } \\
\text { teorias. } \\
\text { 3. Capacidade para distinguir através fato e } \\
\text { teoria. } \\
\text { 4. Conceito de relações causa e efeito. } \\
\text { 5. Habilidade para fazer observações. } \\
\text { 6. Hábito de basear o julgamento em fatos. } \\
\text { 7. Habilidade para formular hipóteses } \\
\text { viáveis. } \\
\text { 8. Disposição de mudar de opinião com } \\
\text { base em novas evidências. } \\
\text { 9. Livre de superstições. } \\
\text { 10. Apreciação das contribuições da ciência } \\
\text { para nossa civilizacão. }\end{array}$ & $\begin{array}{l}\text { 1. Disposição de mudar de opinião com } \\
\text { base em evidências. } \\
\text { 2. Procure toda a verdade, } \\
\text { independentemente de assuntos pessoais, } \\
\text { religiosos, ou preconceito social. } \\
\text { 3. Conceito de relações de causa e efeito. } \\
\text { 4. Hábito de basear o julgamento em fatos. } \\
\text { 5. Poder ou capacidade de distinguir entre } \\
\text { fato e teoria. } \\
\text { 6. Livre de crenças supersticiosas. }\end{array}$ \\
\hline
\end{tabular}

Temas em Educ. e Saúde, Araraquara, v. 16, n. 1, p. 40-50, jan./jun., 2020. e-ISSN 2526-3471. 


\section{Apreciação da beleza natural ou da natureza. \\ 12. Apreciação do lugar do homem no universo. \\ 13. Apreciação dos possíveis desenvolvimentos futuros da ciência. \\ 14. Posse do interesse em ciência.}

Fonte: elaborado pelo autor com base em Anelli (2011, p. 43)

Percebe-se que duas características se "retiram" dos objetivos de estudos, justamente porque caracterizam o "jogo" da ciência, apresentado por Alves (1981), ou seja, a busca da "verdade" - filosofia -, a partir do senso comum e o julgamento sério dos fatos. É a "zona cega", comentada por Morin (2005), sem a qual não há ciência, isso porque ela deverá contextualizar-se, acultura-se em cada local.

O principal ponto, em Chassot (2017) seria a aposta, Uma dica metodológica de Chassot (2017), para pensarmos o currículo, numa proposta de AC que seja aplicável tanto à educação escolar quanto à educação e a formação em espaços fora da escola, deve-se estar entre as duas tendências por ele comentadas, sejam: 1) a articulação entre conhecimento da escola e poder; 2) interseccionalidade entre conhecimento/poder/identidade.

Sintetizando, Chassot (2017), afirma que devemos "[...] nos convencer de que a Educação deve deixar de ser apolítica para ser menos domesticadora e, assim, contribuir para uma alfabetização científica (p. 113)”.

Do estudo teórico empreendido propõe-se pensar a Educação Sexual em CT\&i, começando por uma "adaptação" à Alfabetização Científica (AC). A partir desse conjunto teórico se propõe uma definição provisória do que se denomina, neste estudo, Educação Sexual Científica: “A Educação Sexual é uma ciência, pois, é derivada da Educação, que, por natureza, é científica, é ciência da prática social, é ciência da práxis. O é, e também, deverá ser, pois a Pedagogia e a Didática são, em estatuto, ciência, ramos ou derivações da ciência da educação. Educação Sexual é o ensino científico praxiológico da ciência da sexualidade humana (gênero e diversidades de gênero ou gêneros plurais) no currículo escolar (da educação básica ao ensino superior) e nos espaços não escolares, sejam espaços de empoderamento social e de gênero, sejam nos espaços formativos alavancados pelos movimentos sociais e instâncias partidárias sob o viés do poder e da politização do indivíduo no coletivo. A Educação Sexual é, assim, e pode ser alfabetização científica, tanto do educador(a) quanto do educando; tanto do pesquisador(a) quanto do pesquisado(a)".

Não se trata de discussões entre alfabetização ou letramento. Entende-se que a tensão discursiva já deve ter sido superada. A questão é metodológica, é prática. De forma que poucos 
são os estudos na área do ensino de ciências que vêm, de fato, apresentando metodologias sobre a alfabetização ou letramento científico. Uma rara exceção é o trabalho de Sasseron (2008), que elabora indicadores de alfabetização científica, cujo principal diferencial é ser e apresentar (ter) respostas científicas aos problemas propostos aos estudantes, em conteúdos de Ciências Naturais do Ensino Fundamental.

Indica-se neste trabalho que práticas e metodologias em Educação Sexual se aproximem das bases da CT\&i, superando o aspecto apenas "escolar" pelo "escolar", avançando para aspectos reflexivos, teóricos e metodológicos no âmbito da inovação e no âmbito da tecnologia, tendo a ciência, como eixo propulsor deste "labor".

Certamente, um grande desafio para a Educação Sexual. Quando a preocupação é tanto valorizar o produto industrial em sexualidade humana, quanto refletir sobre seus impactos. E, assim, pensar fundamentos científicos da ciência, da tecnologia e da inovação com foco no sujeito emancipado numa sociedade globalizada.

\section{Considerações finais}

O que temos então a considerar nesse breve estudo propositivo é o seguinte: é possível uma proximidade da Educação Sexual à CT\&i. Esta proximidade deve seguir algumas linhas gerais:

1) a ciência e a produção do conhecimento na área da ciência da sexualidade, da qual, a ciência da práxis, representada pela Educação e, por conseguinte, a Educação Sexual, operacionalizam equações sobre a escolha de uma linha de Epistemologia da Ciência, formatadas num currículo. 2) A ciência da sexualidade, neste caso, é considerada nesta acepção de CT\&i, tanto aquela que se produz no âmbito da história, da filosofia, da antropologia, como também aquela ciência tecnológica e inovadora, que perpassa a indústria e se consolida no mercado, com produtos do prazer ou das tecnologias do prazer.

3) A possível aplicação desta Educação Sexual próxima à CT\&i pode se configurar na Alfabetização Científica. Para isso, o educador(a) sexual é um profissional que foi e é educado cientificamente: conflui tanto os saberes biológicos, quanto os sociais, históricos, filosóficos, antropológicos e consegue dimensionar ao currículo formativo as invenções ou "fatos" da sexualidade social e de mercado.

Este modelo ou discussão teórica é bastante inicial, ainda com nome provisório de "Educação Sexual Científica" busca abranger uma Educação Sexual para além do escolar; 
pretende abarcar a ciência da sexualidade e sua produção de mercado inovador-tecnológico. São ainda, reflexões muito incipientes na proposta de um programa de estudos e debates que, com o tempo, poderão subsidiar reflexões mais aprofundadas e produtos mais específicos, sejam de metodologias ou de produtos, propriamente ditos, que possam ter a envergadura de processos industriais e, nesse caso, a relação da Educação Sexual com as áreas da engenharia, computação, design, são pontos interessantes a serem pensados, além do marketing.

O que se sabe e se conclui é que o caminho desta aproximação da Educação Sexual à CT\&i começa com estudos na área da Filosofia da Ciência, da Epistemologia da Ciência e a escolha de um(a) epistemólogo(a) para "conversar" e iniciar reflexões, bem como caminhos teóricos, perpassados, por exemplo, pela bioética, os Direitos Humanos, saúde, etc.

Portanto, caminhos estão abertos para investigações e aplicações da Educação Sexual com a Alfabetização Científica, como início de um programa de pesquisa em escala micro que permita aproximações bem vindas (ou não) da perspectiva da CT\&i.

Os estudos na área da Educação Sexual encontrarão importantes avanços teóricos e metodológicos na CT\&i e sobre este presente-futuro pouco temos a dizer, a não ser refletir, como os filósofos da Epistemologia da Ciência, que, no momento, são nossos recursos teóricos iniciais. O que se precisa vislumbrar e atentar são os movimentos inovadores da ciência e da indústria do entretenimento, da tecnologia e da sociedade contemporânea. Acompanhar os avanços, sem perder o "veio" da ciência, da ciência da sexualidade, da ciência da educação, da práxis escolar e, portanto, do que se pode conceituar de Educação Sexual Científica, sob as bases da CT\&i no mundo globalizado ou, talvez, o mundo "líquido".

\section{REFERÊNCIAS}

ALVES, R. Filosofia da ciência. Introdução ao jogo e suas regras. São Paulo: Brasiliense, 1981.

ANELLI, C. Scientific Literacy: what is it, are we teaching it, and does it matter? American Entomologist, v. 57, n. 4, p. 235-244, 2011. Disponível em: http://entomology.wsu.edu/wpcontent/uploads/2012/02/Anelli2011scientific-lit.pdf. Acesso em: 29 mar. 2020.

ASIMOV, I. Eu, robô. São Paulo: Aleph, 2014.

BEEDE, D. et al. Women in STEM: a gender gap to innovationation. U.S. Department of Commerce, Economics and Statistics Administration, ago. 2011.

CHASSOT, A. Alfabetização Científica - Questões e Desafios para a Educação. Ijuí: Editora da Unijuí, 2017. 
DAVIS-FLOYD, R.; DUMMIT, J. (Ed.). Cyborg babies: from techno-sex to techno tots. New York: Routledge; 1998.

FOUCAULT, M. História da sexualidade I. A vontade de saber. 13. ed. Rio de Janeiro: Graal, 1988.

HALL, A. R. The historical relations of science and technology. London: Inaugural Lecture, 1963.

HURD, P. D. Scientific literacy: new mind for a changing world. Science \& Education. Stanford, USA, v. 82, n. 3, p. 407-416, 1998. Disponível em: https://eric.ed.gov/?id=EJ565751. Acesso em 30 mar. 2020.

LATOUR, B. Jamais fomos modernos. São Paulo: Ed. 34, 1994.

LATOUR, B. Ciência em ação. São Paulo: Ed. Unesp, 2000.

LATOUR, B. A esperança de Pandora: ensaios sobre a realidade dos estudos científicos, Bauru: Edusc, 2001.

MCARTHUR, N.; TWIST, M. L. C. The rise of digisexuality: therapeutic challenges and possibilities. Sexual and Relationship Therapy, v. 32, n. 3-4, p. 334-344, 2017. Disponível em: https://www.tandfonline.com/doi/abs/10.1080/14681994.2017.1397950. Acesso em 30 mar. 2020.

MORIN, E. Ciência com consciência. 8. ed. Rio de Janeiro: Bertrand Brasil, 2005.

PARKER, R.; AGGLETON, P. Culture, society and sexuality: a reader. 2. ed. New York: Routledge, 2007.

PORTER, R.; TEICH, M. Conhecimento sexual, ciência sexual. História das atitudes em relação à sexualidade. São Paulo: Editora Unesp, 1998.

ROGERS, E. M. Diffusion of innovations. 5. ed. New York: The Free Press, 2003.

RUSSETT, C. E. Sexual Science. The Victorian Construction of Womanhood. Cambridge: Harvard University Press, 1995.

SAMPIERI, R. H.; COLLADO, C. F.; LUCIO, M. P. B. Metodologia da pesquisa. 5. ed. Porto Alegre: Artmed, 2006.

SASSERON, L. H. Alfabetização científica no ensino fundamental: estrutura e indicadores deste processo em sala de aula. 2008. 261 f. Tese (Doutorado em Educação) - Faculdade de Educação da Universidade de São Paulo, São Paulo, 2008.

SCUTT, J.A. Baby machine reproductive technology and the comercialisation of motherhood. London: Green Print; 1990.

WIEZENBAUM, J. Computer power and human reason. San Francisco: Freeman, 1976. 


\section{Como referenciar este artigo}

SILVA, Claudionor Renato da. Educação Sexual, CT\&i: um breve estudo teórico e uma proposta de aplicação. Temas em Educ. e Saúde, Araraquara, v. 16, n. 1, p. 40-50, jan./jun., 2020. e-ISSN 2526-3471. DOI: https://doi.org/10.26673/tes.v16i1.13532

Submetido em: 01/03/2020

Revisões requeridas: 04/05/2020

Aprovado em: 30/06/2020

Publicado em: 19/06/2020 